\title{
Characterization and optimization of oil microcapsules from Attalea phalerata Mart. for the preservation of bioactive compounds
}

\author{
Fernando Freitas de Lima ${ }^{\oplus 1^{*}}$, Caroline Honaiser Lescano ${ }^{\oplus 5}$, Elaine Florinda Rodrigues de

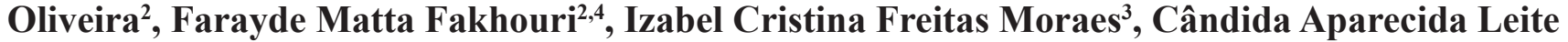 \\ Kassuya $^{6}$, Eliana Janet Sanjinez-Argandoña ${ }^{\circledR 2}$
}

${ }^{1}$ Faculty of Exact Science and Technology, Federal University of Grande Dourados, Dourados, Mato Grosso do Sul, Brazil, ${ }^{2}$ Faculty of Engineering, Federal University of Grande Dourados, Dourados, Mato Grosso do Sul, Brazil, ${ }^{3}$ Faculty of Animal Science and Food Engineering, University of São Paulo, Pirassununga, São Paulo, Brazil, ${ }^{4}$ Faculty of Chemical Engineering,

University of Campinas, Campinas, São Paulo, São Paulo, Brazil, ${ }^{5}$ Faculty of Medical Sciences, University of Campinas, Campinas, São Paulo, Brazil, ${ }^{6}$ Faculty of Health Sciences, Federal University of Grande Dourados, Dourados, Mato Grosso do Sul, Brazil

\begin{abstract}
This study aimed microencapsulating Attalea phalerata Mart. oil, containing high carotenoid and phenolic compounds content, with Arabic gum and gelatin, using the complex coacervation method. The yield, efficiency, morphology of microcapsules and content of phenolic compounds, carotenoids and antioxidant activity in different processes conditions (concentration of the filling, temperature and agitation speed) were evaluated. The results showed $88 \%$ of yield, efficiency up to $70 \%$ and a characteristic size of microcapsules. The amount of carotenoids was high in crude oil (394.84 $\mu \mathrm{g}$ of carotenoids/g oil) and the microencapsulation tests showed amounts of 19.19 to $166.40 \mu \mathrm{g}$ of carotenoids/g oil. The phenolic compounds in the crude oil were $20.73 \mathrm{mg} \mathrm{GAE} / \mathrm{g}$ sample and the microencapsulation tests showed amounts of 3.17 to $15.16 \mathrm{mg} \mathrm{GAE} / \mathrm{g}$ oil. The values of bioactive compounds influenced in the antioxidant activity though $\mathrm{ABTS}^{++}$method with values of $161.70 \mu \mathrm{M}$ trolox/g oil to crude oil and 7.70 and $159.54 \mu \mathrm{M}$ trolox/g oil for microcapsules tests.
\end{abstract}

Keywords: Carotenoids. Phenolic compounds. Antioxidant activity. Bioactive compounds. Bioactive maintenance.

\section{INTRODUCTION}

Microencapsulation acts as an intelligent approach with a strong therapeutic impact, including its specific and attractive characteristics such as, biocompatibility, stability, target specificity, uniform encapsulation and controlled release (Bale et al., 2016). It allows coating the particles or droplets of liquid material forming microcapsules, which protect their content from direct exposure to light, heat and water through encapsulating agents (Cocato et al., 2007; Ferreira et al., 2009). Besides favoring the controlled constituents under specific conditions as well as reducing the liquids

\footnotetext{
*Correspondence: F. Freitas de Lima. Faculdade de Ciências Exatas e Tecnologias, Universidade Federal da Grande Dourados. Rodovia Dourados-Itahum, km 12. Fax:+55-67-99189475. E-mail: flfernando_@hotmail.com
}

volatility (Menezes et al., 2013) and extending the life of the core material (Nori et al., 2011), which enable microencapsulated products to have better applicability. This is a very promising technique in preserving bioactive compounds, which are of great importance for human health, and, so it is important to optimize the ideal process and conditions to microencapsulating these compounds.

The oil of Attalea phalerata Mart. (Arecaceae), widely known as bacuri, is a palm tree commonly found in Brazil. It has a high nutritional value with antiinflammatory properties and there are only a few studies related to its bioactive compounds (Freitas de Lima et al., 2016; De Lima et al., 2017; De Lima et al., 2018). Among the most relevant compounds, there are the phenolic compounds and carotenoids. These constituents and their advantageous health effects arouse the interest of the 
scientific community. Among the biological activities attributed to these compounds, they play a relevant role in boosting the immune system (Gomes, 2007) and in the reduction of degenerative diseases such as diabetes, cardiovascular problems, inflammatory processes, among others (Rodriguez-Amaya, 2010).

However, certain limitations related to the stability of bioactive compounds can be observed, such as the lipid peroxidation in the carotenoids (Rodriguez-Amaya, 2010) and enzymatic browning in the phenolic compounds (Zhang et al., 2015). In an attempt to avoid the degradation of these compounds, technologies such as microencapsulation have emerged (Kralovec et al., 2012), furthermore, oils have hydrophobic characteristics which limit their application in food. Therefore, the encapsulated form can facilitate their solubility and application in different food products. The aim of this work was to produce and characterize microcapsules of Attalea phalerata Mart. oil through complex coacervation technique and evaluate the influence of the process on the content of bioactive compounds and antioxidant activity of the microencapsulated material.

\section{MATERIAL AND METHODS}

\section{Sample preparation}

Attalea phalerata Mart. fruits were collected in Bonito - MS (Brazil), latitude $21^{\circ} 10^{\prime} 19.1$; longitude $056^{\circ} 26^{\prime} 58.0$ and altitude $6 \mathrm{~m}$. The voucher specimen of the species was deposited in the Herbarium UFGD No. DDMS5033. After selection, the fruits were washed with tap water and sanitized with a solution of sodium dichloroisocyanurate $0.66 \%$. The fruits were then peeled, pulped and the pulp was subsequently dried in an oven at $40{ }^{\circ} \mathrm{C}$ with an air flow of $0.5 \mathrm{~m} / \mathrm{s}$ for 72 hours. The dried material was crushed, sieved through a sieve with apertures of 20 mesh for powder uniformity, subsequently packaged and stored at room temperature.

\section{Oil extraction}

The $A$. phalerata oil was obtained by solid-liquid extraction with hexane solvent at a ratio of one part of dewatered pulp powder to 3 parts of solvent $1: 3(\mathrm{w} / \mathrm{v})$ under continuous stirring (150 rpm) for 7 days. The product was filtered and the solvent removed on a rotary evaporator under reduced pressure at $50{ }^{\circ} \mathrm{C}$. The oil was then packaged in amber bottle and stored at $9 \pm 2{ }^{\circ} \mathrm{C}$.

\section{Preparation of microcapsules}

The microcapsules of $A$. phalerata oil were prepared through the complex coacervation method in aqueous medium (Alvim, 2005), with some modifications. Microcapsules were produced from nine formulations, as defined in factorial design $2^{3}$ (Table I) with three independent variables: filling (amount of $A$. phalerata oil), homogenization speed and temperature. The response variables were yield, microencapsulation efficiency, size of microcapsules, content of phenolic compounds, carotenoids and antioxidant activity.

\section{Yield of microencapsulation process}

The yield (R) was calculated from the separation of the phases obtained in microencapsulation (supernatant and pellet). The microcapsules were centrifuged at 15000 rpm for fast compression and the supernatant was removed and sieved through a sieve with apertures of 200 mesh for complete separation of the supernatant and pellet (microcapsules). The sediment was then weighed and the yield was calculated through equation 1 (Barbosa, 2009).

$$
(\%)=\frac{\mathrm{SM}}{\mathrm{TM}} \times 100 \quad \text { Equation } 1
$$

Sedimented microcapsule (g), and TM is the theoretical mass consisting of Arabic gum + gelatin + oil $(\mathrm{g})$, both in dry basis.

\section{Efficiency of microencapsulation}

The efficiency of the microencapsulation (EM) was determined based on Bueno (2008), considering the total

TABLE I - Factorial design $2^{3}$ for obtaining microcapsules by complex coacervation of bacuri oil

\begin{tabular}{|c|c|c|c|}
\hline \multirow{2}{*}{ Independent variables } & \multicolumn{2}{|c|}{ Factorial Points } & \multirow{2}{*}{$\begin{array}{c}\text { Central Point } \\
0\end{array}$} \\
\hline & -1 & +1 & \\
\hline Core $(\mathrm{g} / 600 \mathrm{~mL})$ & 5 & 10 & 7.5 \\
\hline Temperature $\left({ }^{\circ} \mathrm{C}\right)$ & 40 & 60 & 50 \\
\hline Homogenization speed (rpm) & 12000 & 18000 & 15000 \\
\hline
\end{tabular}


lipid content. The efficiency was defined as the amount of oil present in a gram of microcapsule related to the amount initially introduced into the oil microencapsulation process, according to equation 2 .

$$
\mathrm{EM}(\%)=\frac{\mathrm{AOE}}{\mathrm{AOI}} \times 100 \quad \text { Equation } 2
$$

where: AOE is the amount of oil extracted $(\mathrm{g})$ of the formed microcapsules and AOI is the amount of oil introduced $(\mathrm{g})$.

\section{Morphology and size}

The morphology of the microcapsules outer surface was evaluated by optical microscopy using a microscope coupled to a camera (Nikon Eclipse - 200). Samples of each formulation were obtained in the form of photomicrographs. The size of the microcapsules was determined by the length and width diameters of particles displayed in the photomicrographs enlarged in a microscope objective of $40 \mathrm{x}$. A hundred and fifty microcapsules were analyzed, and in case of non-spherical particle, the size was standardized by the average diameters. The images and data were analyzed by the software Image Pro Plus 4.0.

\section{Scanning electron microscopy}

The samples were coated in a Sputter Coater POLARON, Model: SC7620, Brand: VG Microtech (Uckfield, England). The thickness of the Au layer followed the equation: Thickness $=$ K.i.V.t, where $\mathrm{K}=0.17 \mathrm{~A} / \mathrm{mA}$. Volt. $\mathrm{s} ; \mathrm{i}=3 \mathrm{~mA} ; \mathrm{V}=1$ Volt and $\mathrm{t}=180 \mathrm{~s}$. $\left(92 \mathrm{~A}^{\circ}\right)$. The coated samples were analyzed on a Scanning Electron Microscope with Energy Dispersive Detector of X-ray (Model MEV: Leo 440i, Model EDS: 6070, Brand MEV/EDS: LEO Electron Microscopy/Oxford (Cambridge, England)). We used accelerating voltage of $10 \mathrm{kV}$ and beam current of $100 \mathrm{~mA}$ to obtain micrographs of tension.

\section{Determination of bioactive compounds}

\section{Carotenoids}

Samples (microcapsules or oil) were weighed and macerated with the aid of Hyflosupercel, and then acetone was added until extracting all the pigment; the mixture was then vacuum-filtered. The extract was collected then transferred to a separation funnel. The mixture was slowly washed with distilled water until complete removal of the acetone. The material was transferred into a volumetric flask and the volume completed with petroleum ether. Readings of absorbance at $450 \mathrm{~nm}$ were made (Rodriguez-Amaya, 2010). The content of carotenoids was calculated through equation 3 .

$$
\mathrm{C}(\mu \mathrm{g} / \mathrm{g})=\frac{\lambda \times \mathrm{D} \times 10}{\varepsilon \times \mathrm{m}(\mathrm{g})} \quad \text { Equation } 3
$$

where $\lambda$ is absorbance $(\mathrm{nm}), \mathrm{D}$ is dilution $(\mathrm{mL}), \varepsilon$ is $\beta$-carotene factor in petroleum ether (2592) and $\mathrm{m}$ is sample weight $(\mathrm{g})$.

\section{Phenolic Compounds}

The quantification of the phenolic compounds was performed with the reagent Follin-Ciocauteau, according to Georgé et al. (2005). The extract was prepared with sample (microcapsules or oil) and acetone, the mixture was centrifuged and supernatant was collected. An aliquot of the extract was mixed with distilled water, aqueous solution of Folin-Ciocalteu and sodium carbonate. The mixture was incubated in a water bath and, after the cooling, the absorbance was measured at $760 \mathrm{~nm}$. Phenolic compounds were determined by interpolation of the samples absorbance's against a calibration curve constructed from standards of gallic acid $(0.025,0.035,0.045,0.055$ and $0.065 \mathrm{mg} / \mathrm{mL})$. The equation of the calibration curve of gallic acid was $13.0100 \mathrm{~A} \mathrm{C}=+0.0478$, where $\mathrm{C}$ is the concentration of gallic acid, $\mathrm{A}$ is the absorbance at $760 \mathrm{~nm}$ with a correlation coefficient $(\mathrm{R})$ of 0.999 . The results were expressed as mg GAE (gallic acid equivalents)/g extract. Each determination was performed in triplicate.

\section{Evaluation of antioxidant activity by ABTS*+ method}

The extracts were prepared from the mix of microcapsules and oils and hydromethanolic solution $(50 \%)$. After standing for 60 minutes, the material was centrifuged and the supernatant removed. Acetone was added to the sediment in order to perform the second extraction following the steps of the first extraction. The supernatants from the extractions were mixed, transferred to a flask and the volume completed with distillated water. Aliquots of extract were added to dilute $\mathrm{ABTS}^{-+}$and the absorbance of the mixture was recorded after 6 min. A calibration curve was prepared from ethanolic solutions of Trolox (6-hydroxy-2,5,7,8tetrametilchroman-2-carboxylic acid) at concentrations of $100 ; 500 ; 1000 ; 1500$ and $2000 \mu \mathrm{M}$ (Maria do Socorro et al., 2010). The equation of the calibration curve 
was $\mathrm{C}=-0.0002 \mathrm{~A}+0.3049$, with a correlation coefficient (R) of 0.999 , in which $\mathrm{C}$ is concentration of Trolox and A is absorbance at $734 \mathrm{~nm}$. The results were expressed in $\mathrm{mM}$ Trolox/g extract. Each determination was carried out in triplicate.

\section{Statistical analysis}

The formulations were carried out according to the factorial design of $2^{3}$, consisting of six experiments for each formulation. The averages were evaluated by analysis variance (ANOVA), comparison of averages was performed through Tukey test $(\mathrm{p} \leq 0.05)$ using Statistica 8.0 software. For the response surface was used the same statistical method software as the other data.

\section{RESULTS AND DISCUSSION}

\section{Yield and efficiency}

Table II shows the effect of the amount of Attalea phalerata Mart. oil loaded, the process temperature and the homogenization speed of the emulsion on the yield and on the efficiency and size of the microcapsules.

Test 1 differed significantly to the tests 6 and 8 $(\mathrm{p} \leq 0.05)$, which presented a yield above $80 \%$. The temperature influenced the phase separation since, in general, the best results were obtained at $40{ }^{\circ} \mathrm{C}$. According to Prata and Grosso (2015), lower temperatures favor the phase separation. However, it is noteworthy that high yield levels are not correlated with high efficiency, since not all microcapsules exhibit filling (oil) inside. This was best evaluated through the microcapsule morphology, since the best yield results were in the low temperature formulations and these same formulations were not fully stable to the extent of forming microcapsules.

Regarding the efficiency of the oil microencapsulation, values between $18.76 \%$ and $70.72 \%$ were found. Tests 6 and 8 did not differ from each other $(\mathrm{p} \geq 0.05)$, but they were significantly different from the others at $5 \%$, with higher efficiency $(65.63 \%$ and $70.72 \%$, respectively). These same tests ( 6 and 8 ) also showed elevated yield levels, as depicted in Table I. The microencapsulation process of $A$. phalerata oil by complex coacervation was optimized in formulation 8 , which allowed to validate and analyze all the tests responses of the phenolic compounds and carotenoids. For the first time, A. phalerata oil is microencapsulated with high yield and efficiency, since the complex coacervation method is considered inexpensive and well adaptive to industrial conditions, increasing its applicability.

\section{Morphology and size}

The average size of coacervates capsules of $A$. phalerata oil ranged from 33.59 to $86.80 \mu \mathrm{m}$ (Table II), characterizing the microcapsules for having less than $500 \mu \mathrm{m}$ size (Favaro-Trindade, Pinho, Rocha, 2008). The sizes of the formed microcapsules were similar to those observed by Nori et al. (2011) in the microencapsulation of propolis extract by complex coacervation, where the authors obtained sizes from 10.00 to $90.00 \mu \mathrm{m}$.

TABLE II - Effect of the amount of oil (core), temperature and homogenization speed on the yield, encapsulation efficiency and size of the bacuri pulp oil microcapsules obtained by complex coacervation

\begin{tabular}{|c|c|c|c|c|c|c|}
\hline \multicolumn{4}{|c|}{ Independent Variables } & \multicolumn{3}{|c|}{ Dependent Variables } \\
\hline Test & $\begin{array}{c}\text { Filling } \\
\text { (g/600 mL) }\end{array}$ & $\begin{array}{c}\text { Temperature } \\
\left({ }^{\circ} \mathrm{C}\right)\end{array}$ & Speed (rpm) & Yield (\%) & $\begin{array}{l}\text { Encapsulation } \\
\text { efficiency (\%) }\end{array}$ & Size $(\mu \mathrm{m})$ \\
\hline 1 & 5 & 40 & 12000 & $88.85^{\mathrm{e}} \pm 1.08$ & $32.07^{b} \pm 2.67$ & $86.80^{\mathrm{c}}$ \\
\hline 2 & 10 & 40 & 12000 & $85.10^{\mathrm{de}} \pm 1.94$ & $50.38^{\mathrm{d}} \pm 3.49$ & $59.77^{\mathrm{b}}$ \\
\hline 3 & 5 & 60 & 12000 & $79.31^{\mathrm{c}} \pm 0.25$ & $50.70^{\mathrm{d}} \pm 2.64$ & $33.59^{\mathrm{a}}$ \\
\hline 4 & 10 & 60 & 12000 & $74.83^{b} \pm 3.29$ & $18.76^{\mathrm{a}} \pm 0.18$ & $45.24^{\mathrm{ab}}$ \\
\hline 5 & 5 & 40 & 18000 & $67.58^{\mathrm{a}} \pm 1.26$ & $20.66^{\mathrm{a}} \pm 1.01$ & $38.37^{\mathrm{a}}$ \\
\hline 6 & 10 & 40 & 18000 & $82.60^{\mathrm{cd}} \pm 2.07$ & $65.63^{\mathrm{e}} \pm 1.85$ & $83.68^{\mathrm{c}}$ \\
\hline 7 & 5 & 60 & 18000 & $74.16^{\mathrm{b}} \pm 1.46$ & $44.56^{\mathrm{c}} \pm 3.94$ & $45.33^{\mathrm{ab}}$ \\
\hline 8 & 10 & 60 & 18000 & $82.55^{\mathrm{cd}} \pm 0.26$ & $70.72^{\mathrm{e}} \pm 0.90$ & $50.81^{\mathrm{ab}}$ \\
\hline 9 & 7.5 & 50 & 15000 & $72.86^{\mathrm{b}} \pm 3.90$ & $34.85^{\mathrm{b}} \pm 1.89$ & $34.42^{\mathrm{a}}$ \\
\hline
\end{tabular}

Means \pm standard deviation of tests performed in triplicate. Means followed by different letters in the same column differ statistically by Tukey test $(\mathrm{p} \leq 0.05)$. 
The morphological characteristics varied significantly $(\mathrm{p} \leq 0.05)$ as a function of temperature and homogenization speed. More homogeneous microcapsules were obtained under the process conditions of $10 \mathrm{~g}$ filling, $60{ }^{\circ} \mathrm{C}$ and $18000 \mathrm{rpm}$ homogenization speed (Figure 1A).

The emulsion's homogenization speed was an important parameter in the microcapsules formation; high speeds tend to provide more stable emulsions, resulting in morphological uniform microcapsules (Laine et al., 2011). The speed reduction of homogenization resulted in less spherical microcapsules (Figure 1B) and the temperature reduction from $60^{\circ} \mathrm{C}$ to $40^{\circ} \mathrm{C}$ also decreased the formation of microcapsules (Figure 1C).

Figure 2 shows the scanning electron microscopy of tests $6\left(10 \mathrm{~g}, 40^{\circ} \mathrm{C}, 18000 \mathrm{rpm}\right)$ and $8\left(10 \mathrm{~g}, 60^{\circ} \mathrm{C}\right.$, $18000 \mathrm{rpm})$. Based on images, it can be observed the rounded shape of the microcapsules obtained as well as their resistance to heat-treatment. The figures show that the
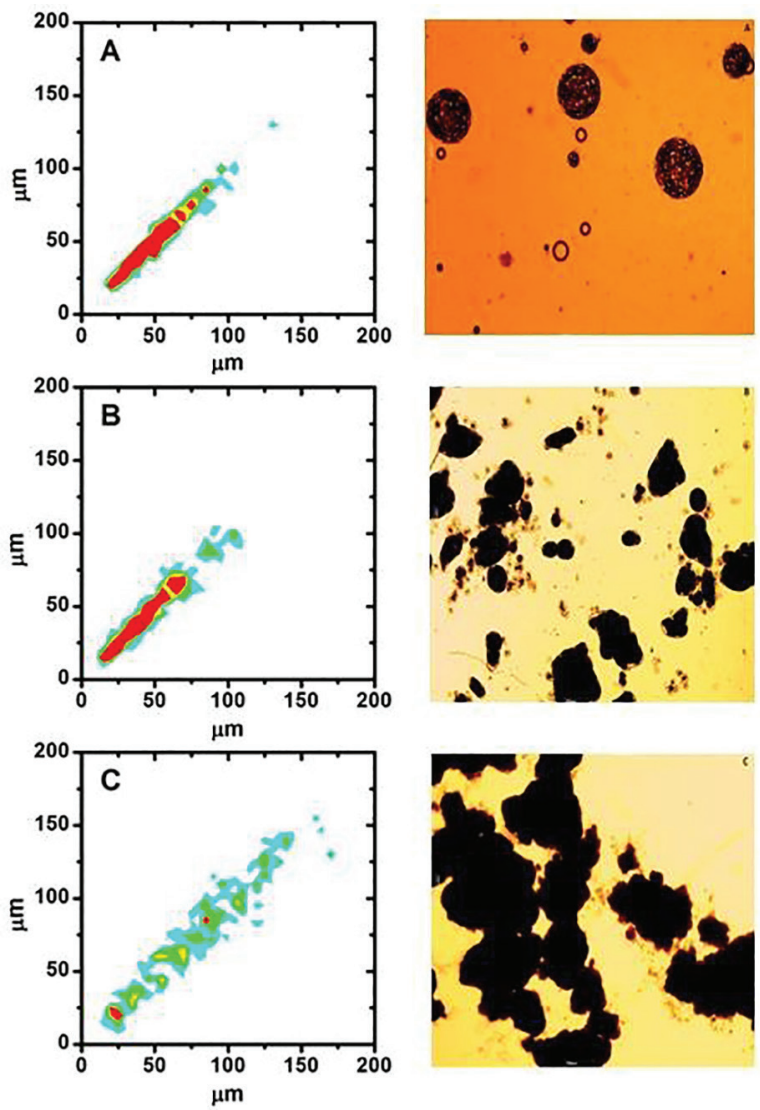

FIGURE 1 - Map of the distributions size and image of microcapsules coacervates with Attala phalerata Mart. oil under coacervation conditions: (A) $10 \mathrm{~g}$ core, $60^{\circ} \mathrm{C}$ temperature, homogenization speed $18000 \mathrm{rpm}$; (B) $10 \mathrm{~g}$ core, $60{ }^{\circ} \mathrm{C}$ temperature, homogenization speed $12000 \mathrm{rpm}$; (C) $10 \mathrm{~g}$ core, $40{ }^{\circ} \mathrm{C}$ temperature, homogenization speed $18000 \mathrm{rpm}$ increased on 40x in Optical Microscopy.

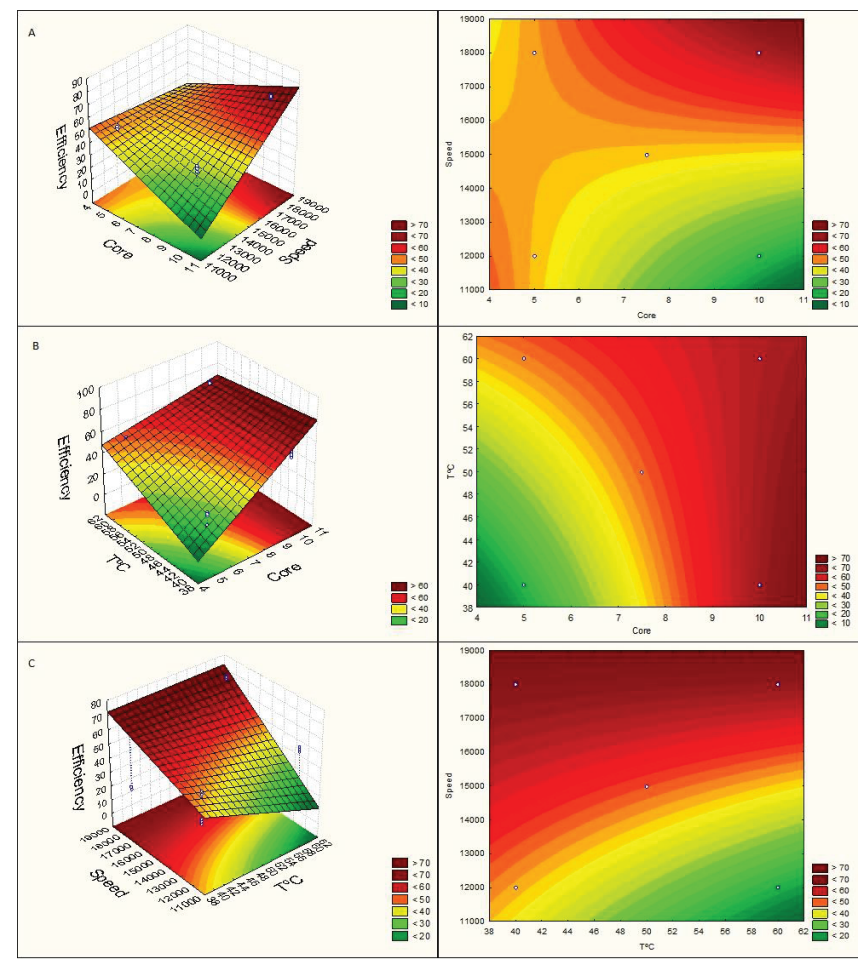

FIGURE 2 - Image of microcapsules coacervates with A. phalerata Mart. oil under coacervation conditions: (A and B) $10 \mathrm{~g}, 40^{\circ} \mathrm{C}, 18000 \mathrm{rpm}$; (C and D) $10 \mathrm{~g}, 60^{\circ} \mathrm{C}, 18000 \mathrm{rpm}$ increased on $2.500 \mathrm{Kx}$ in Scanning Electron Microscopy.

particles did not attach, keeping their original formulation, which can be cooperated with the highest content of phenolic compounds (test 8) of such formulations when they were analyzed and on the higher carotenoid content observed by test 6 (Figure 2AB).

\section{Response surface}

The microencapsulation parameters are specific, as the yield and efficiency of the microencapsulation may vary for being influenced by the chemical composition and viscosity of the filling (oil) (Cheng et al., 2010; Jun-xia, Hai-yan, Jian, 2011; Wieland-Berghausen et al., 2002). To evaluate the effects of core concentration and of the temperature and speed of homogenization on the efficiency (Figure 3), test 8 conditions were taken into consideration $\left(10 \mathrm{~g}, 60^{\circ} \mathrm{C}\right.$ and $\left.18000 \mathrm{rpm}\right)$ for presenting better morphology than test 6 microcapsules.

Figure $3 \mathrm{~A}$ shows the effects of the amount of filling and homogenization speed on the efficiency of microencapsulation at $60^{\circ} \mathrm{C}$. Increased amount of filling only took effect when the homogenization speed was also increased (Figure 3). This may be due to the large amount of oil, showing that the agitation favors the contact surface between the oil and the encapsulating polymer. 
The influence of the filling and temperature in the formation of coacervated microcapsules at $18000 \mathrm{rpm}$ is observed in Figure 3B. The encapsulation efficiency was higher on increased filling concentration, disregarding the temperature. Figure $3 \mathrm{C}$ shows the influence of the encapsulation temperature and speed of $10 \mathrm{~g} / 600 \mathrm{~mL}$ of $A$. phalerata oil. Greater efficiency is observed on increased temperature and homogenization speed, which can be explained by the change in the oil viscosity and fluidity. The decrease of viscosity on increased temperature was also observed by (Grangeiro et al., 2007). The authors attributed this to the increase of intermolecular distances caused by heating.

Apparently, the lower the oil viscosity, the higher the yield of microencapsulation; possibly due to the larger displacement of the fluid particles, which allows a more homogeneous distribution of oil particles and higher availability of the crosslinked. The influence of oil viscosity on microencapsulation was presented by Prata and Grosso (2015) on the study of microcapsules produced by complex coacervation of three oils (vetiver, almonds and mineral oil) with different viscosities. The authors obtained higher encapsulation efficiency $(91.8 \%)$ for the least viscous oil (vetiver).

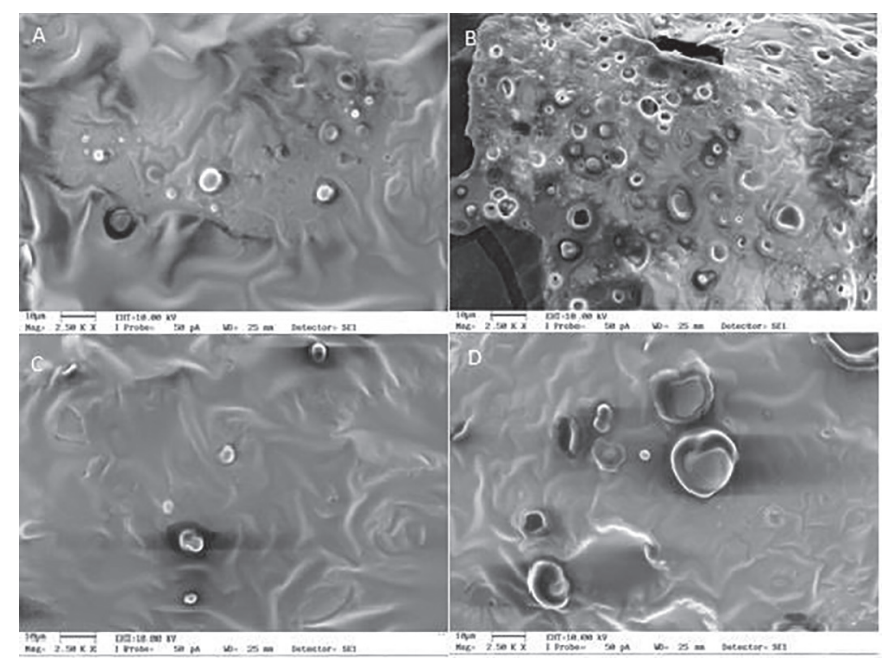

FIGURE 3 - Efficiency of the formation of $A$. phalerata Mart. pulp oil microcapsules: (A) core vs. speed at $60^{\circ} \mathrm{C}$; (B) core vs temperature at $18000 \mathrm{rpm} ;(\mathrm{C})$ temperature vs. speed with $10 \mathrm{~g}$.

\section{Bioactive compounds and antioxidant activity}

The carotenoid content in the microcapsules ranged from $19.19 \mathrm{a} 166.40 \mu \mathrm{g} / \mathrm{g}$ of dry microcapsule on dry mass (Figure 4A). The content of carotenoids in A. phalerata crude oil was $394.84 \mu \mathrm{g} / \mathrm{g}$ oil (dry mass). Tests 2 (10 g, $\left.40{ }^{\circ} \mathrm{C}, 12000 \mathrm{rpm}\right)$ and $6\left(10 \mathrm{~g}, 40^{\circ} \mathrm{C}, 18000 \mathrm{rpm}\right)$ showed greater retention when compared to the other tests. The loss of carotenoids in the microcapsules can be directly attributed to exposure to oxygen during the formation of the emulsion with the homogenization speed, which may have caused the oxidation of this biosensor. The reduction of carotenoids by oxidation was also observed by CasteloBranco and Torres (2011).

Regarding the phenolic compounds, $A$. phalerata crude oil presented $20.73 \mathrm{mg}$ GAE/g sample (extract). Maria do Socorro et al. (2010), in A. phalerata pulp in nature, quantified $13.65 \mathrm{mg} \mathrm{GAE} / \mathrm{g}$ extract, a lower value than found in the present study. The content of phenolic compounds found in almond oil of other species shows that A. phalerata has higher values (Figure 4B). For the cutia almond (Couepia Prance Edulis), Costa-Singh, Bitrncourt and Jorge et al. (2012) obtained $2.02 \mathrm{mg} \mathrm{GAE} / \mathrm{g}$ oil and from oil extracted in pecan (Carya illinoensis (Wang.)), Alasalvar and Shahidi (2009) reported $0.78 \mathrm{mg}$ GAE/g oil.

However, the amount of carotenoids in the oil and microcapsules was higher in relation to phenolic compounds, which can be justified by the hydrophilic character of the phenolic compounds. Such hydrophilicity can hinder its determination in oils, unlike carotenoids, which are part of the lipophilic fractions (Castelo-Branco, Torres, 2011). Although most of the phenolic compounds are water soluble and are connected to sugars and proteins; tocopherols are phenolic compounds mostly found in oil seeds (Shahidi, Janitha, Wanasundar, 1992).

The greater retention of phenolic compounds in the microcapsules was observed in tests $6\left(10 \mathrm{~g}, 40^{\circ} \mathrm{C}\right.$, $18000 \mathrm{rpm}), 8\left(10 \mathrm{~g}, 60^{\circ} \mathrm{C}, 18000 \mathrm{rpm}\right)$ and $9\left(7.5 \mathrm{~g}, 50^{\circ} \mathrm{C}\right.$, $15000 \mathrm{rpm})$. The homogenization speed did not influence the retention, however, the quantity of oil included in the process was significant $(p \leq 0.05)$. In the microcapsules obtained at $40{ }^{\circ} \mathrm{C}$ with $10 \mathrm{~g}$ of filling (test 6 ) the content of carotenoids was greater $(140.79 \mu \mathrm{g} / \mathrm{g}$ microcapsule $)$ and at $60{ }^{\circ} \mathrm{C}$ (test 8 ) phenolic compounds were greater $(15.16 \mathrm{mg} / \mathrm{g}$ extract GAE). The tests show that temperature have a greater influence on the amount of carotenoids than in phenolic compounds and, consequently, in the antioxidant activity.

The values of the antioxidant activity by $\mathrm{ABTS}^{\cdot+}$ method to the crude oil was $161.70 \mu \mathrm{M}$ trolox/g extract (Figure 5), under different conditions (amount of filling, temperature and homogenizing speed) the value ranged between 7.70 and $159.54 \mu \mathrm{M}$ trolox $/ g$ extract. In test 6 $\left(10 \mathrm{~g}, 40^{\circ} \mathrm{C}, 18000 \mathrm{rpm}\right)$ and $8\left(10 \mathrm{~g}, 60^{\circ} \mathrm{C}, 18000 \mathrm{rpm}\right)$ the antioxidant activity was superior to the others, the result of antioxidant activity indicates high antiradical potential of the microcapsules of $A$. phalerata oil, demonstrating the nutritional and bioactive importance of native species of Brazilian Cerrado. 
Despite the slight reduction of the levels of bioactive compounds, a crucial factor that microencapsulation proposes is the controlled release which ensures the release of carotenoids and phenolic compounds in the intestine after consumption, thereby avoiding the exposure of these compounds to conditions that lead to their degradation. There are evidences that microencapsulation of bioactive compounds such as tocopherols and carotenoids have been able to gradually increase their release, promoting an increased absorption (Luo et al., 2011; Rutz et al., 2017).
Therefore, A. phalerata pulp oil can be used as a core material to produce microcapsules in order to maintain the bioactive compounds, as well as represents a promising alternative for food additive in its incorporation into functional foods due to retention of its antioxidant activity.

\section{CONCLUSION}

The experimental design shows that temperature increases the filling, and concentration generally increases
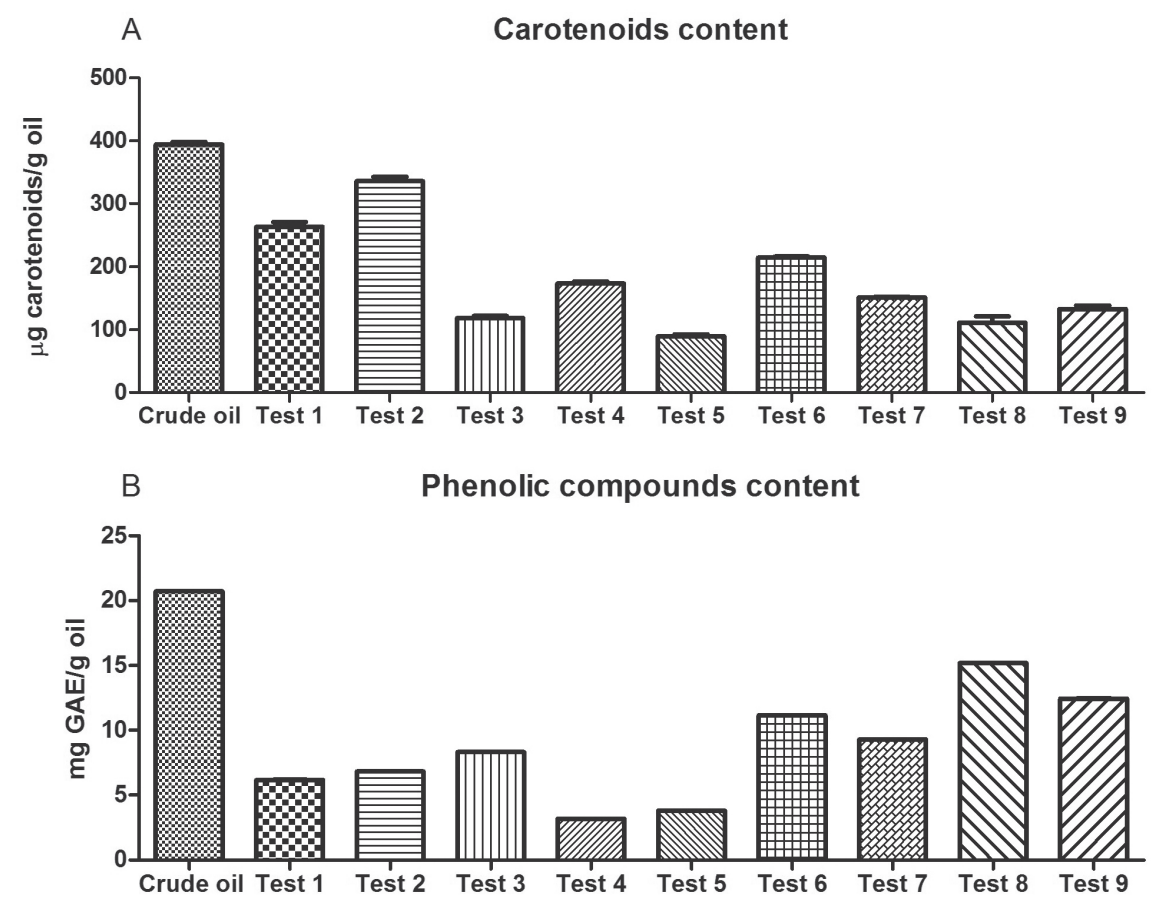

FIGURE 4 - Total carotenoids (A) and phenolic compounds (B) of Attalea phalerata Mart. pulp oil (crude and microcapsules), obtained by complex coacervation at different process conditions. Means of tests performed in triplicate. Test $1\left(5 \mathrm{~g}, 40^{\circ} \mathrm{C}\right.$, $12000 \mathrm{rpm})$, test $2\left(10 \mathrm{~g}, 40^{\circ} \mathrm{C}, 12000 \mathrm{rpm}\right)$, test $3\left(5 \mathrm{~g}, 60^{\circ} \mathrm{C}, 12000 \mathrm{rpm}\right)$, test $4\left(10 \mathrm{~g}, 60^{\circ} \mathrm{C}, 12000 \mathrm{rpm}\right)$, test $5\left(5 \mathrm{~g}, 40^{\circ} \mathrm{C}\right.$, $18000 \mathrm{rpm})$, test $6\left(10 \mathrm{~g}, 40^{\circ} \mathrm{C}, 18000 \mathrm{rpm}\right)$, test $7\left(5 \mathrm{~g}, 60^{\circ} \mathrm{C}, 18000 \mathrm{rpm}\right)$, test $8\left(10 \mathrm{~g}, 60^{\circ} \mathrm{C}, 18000 \mathrm{rpm}\right)$ and test $9\left(7.5 \mathrm{~g}, 50^{\circ} \mathrm{C}\right.$, $18000 \mathrm{rpm})$.

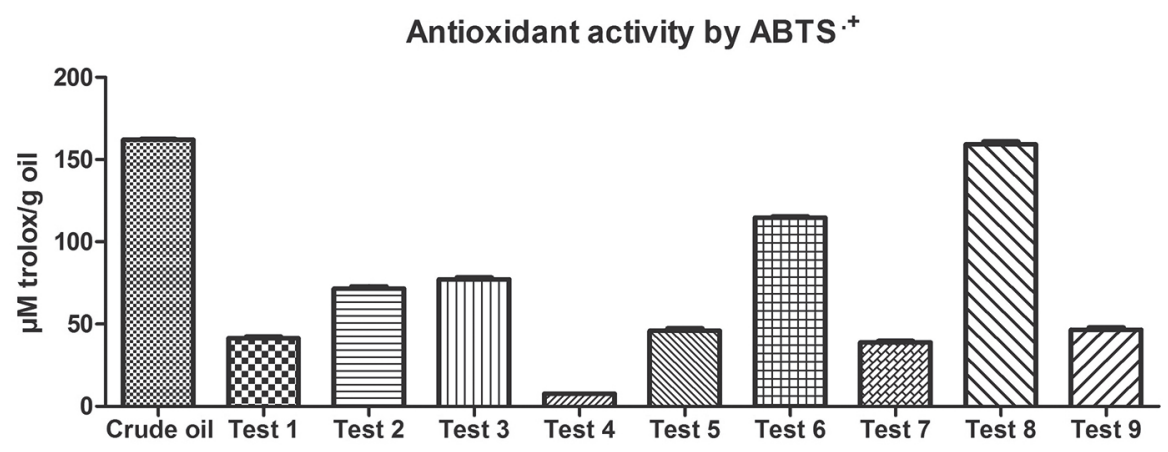

FIGURE 5 - Antioxidant activity of Attalea phalerata Mart. pulp oil (crude and microcapsules) by $\mathrm{ABTS}^{\circ+}$ method, obtained by complex coacervation at different process conditions. Means of tests performed in triplicate. Test $1\left(5 \mathrm{~g}, 40^{\circ} \mathrm{C}, 12000 \mathrm{rpm}\right)$, test 2 $\left(10 \mathrm{~g}, 40^{\circ} \mathrm{C}, 12000 \mathrm{rpm}\right)$, test $3\left(5 \mathrm{~g}, 60^{\circ} \mathrm{C}, 12000 \mathrm{rpm}\right)$, test $4\left(10 \mathrm{~g}, 60^{\circ} \mathrm{C}, 12000 \mathrm{rpm}\right)$, test $5\left(5 \mathrm{~g}, 40^{\circ} \mathrm{C}, 18000 \mathrm{rpm}\right)$, test $6(10 \mathrm{~g}$, $\left.40{ }^{\circ} \mathrm{C}, 18000 \mathrm{rpm}\right)$, test $7\left(5 \mathrm{~g}, 60^{\circ} \mathrm{C}, 18000 \mathrm{rpm}\right)$, test $8\left(10 \mathrm{~g}, 60^{\circ} \mathrm{C}, 18000 \mathrm{rpm}\right)$ and test $9\left(7.5 \mathrm{~g}, 50^{\circ} \mathrm{C}, 18000 \mathrm{rpm}\right)$ 
the efficiency and yield of the process. Microencapsulation by complex coacervation of $A$. phalerata oil had higher efficiency and yield with $10 \mathrm{~g} / 600 \mathrm{~mL}$ of filling, temperature at $60{ }^{\circ} \mathrm{C}$ and homogenization speed of $18000 \mathrm{rpm}$, as determined by response surface. Under these conditions, yield and encapsulation efficiency were of $82.55 \%$ and $70.72 \%$, respectively. The microcapsules were $50.81 \mu \mathrm{m}$ in size and the scanning electron microscopy showed particles with rounded shape. The Attalea phalerata Mart oil pulp presented a high carotenoid content and antioxidant activity. When phenolic compounds and carotenoids were assessed, the obtained microcapsules were able to retain the bioactive compounds, maintaining the antioxidant activity.

\section{ACKNOWLEDGEMENTS}

To Coordenação de Aperfeiçoamento de Pessoal de Nível Superior (CAPES) for scholarship assistance, to Fundação de Apoio ao Desenvolvimento do Ensino, Ciência e Tecnologia do Estado de Mato Grosso do Sul (FUNDECT) and to Conselho Nacional de Desenvolvimento Científico e Tecnológico (CNPq) for the equipment and to Grupo de Estudos em Produtos e Processos Agroindustriais do Cerrado (GEPPAC) for cooperation provided to the analyzes.

\section{REFERENCES}

Alasalvar C, Shahidi F. Natural antioxidants in tree nuts. Eur J Lipid Sci Tech. 2009;111(11):1056-62.

Alvim ID. Produção e caracterização de microparticulas obtidas por spray drying e coacervação complexa e seu uso para alimentação de larvas de peixes. [tese]. Campinas: Universidade Estadual de Campinas, Faculdade de Engenharia de Alimentos; 2005.

Bale S, Khurana A, Reddy AS, Singh M, Goducu C. Overview on Therapeutic applications of microparticulate drug delivery systems. Crit Rev Ther Drug. 2016;33(4):309-61.

Barbosa MIMJ. Microcapsulas de bixina: obtenção, aplicação e estudos de fotodegradação em sistemas-modelo. [tese]. Campinas: Universidade Estadual de Campinas, Faculdade de Engenharia de Alimentos; 2009.

Bueno CMM. Extração e caracterização de gelatina de pele de tilapia e aplicação como agente encapsulante de oleo de salmão em microparticulas obtidas por coacervação complexa. [dissertação]. Campinas: Universidade Estadual de Campinas, Faculdade de Engenharia de Alimentos; 2008.
Castelo-Branco VN, Torres AG. Capacidade antioxidante total de óleos vegetais comestíveis: determinantes químicos e sua relação com a qualidade dos óleos. Rev Nutr. 2011;24(1):17387.

Cheng S-Y, Yuen MC-W, Lam P-L, Gambari R, Wong, RS-M, Cheng GY-M, et al. Synthesis, characterization and preliminary analysis of in vivo biological activity of chitosan/celecoxib microcapsules. Bioorg Med Chem Lett. 2010;20(14):4147-51.

Cocato ML, Ré MI, Trindade Neto MA, Chiebao HP, Colli C. Avaliação por métodos in vitro e in vivo da biodisponibilidade de sulfato ferroso microencapsulado. Rev Nutr. 2007;20(3):23947.

Costa-Singh T, Bitrncourt TB, Jorge N. Caracterização e compostos bioativos do óleo da castanha-de-cutia (Couepia edulis). Rev Inst Adolfo Lutz (Impr.). 2012;71(1):61-8.

De Lima FF, Traesel GK, Menegati SELT, dos Santos AC, Souza RIC, de Oliveira VS, et al. Acute and subacute oral toxicity assessment of the oil extracted from Attalea phalerata Mart ex Spreng. pulp fruit in rats. Food Res Int. 2017;91:11-17.

De Lima FF, Lescano CH, da Silva Arrigo J, Cardoso CAL, Coutinho JP, Moslaves ISB, et al. Anti-inflammatory, antiproliferative and cytoprotective potential of the Attalea phalerata Mart. ex Spreng. pulp oil. PloS One. 2018;13(4):e0195678.

Favaro-Trindade CS, Pinho S, Rocha G. Revisão: Microencapsulação de ingredientes alimentícios. Braz J Food Technol. 2008;11(2):103-12.

Ferreira DS, Faria AF, Grosso CRF, Mercadante AZ. Encapsulation of blackberry anthocyanins by thermal gelation of curdlan. J Braz Chem Soc. 2009;20(10):1908-15.

Freitas de Lima F, Lima Tolouei Menegati SE, Karenina Traesel G, Souza de Araújo FH, Honaiser Lescano C, Moraes Peixoto S, et al. Study on the cytotoxic, genotoxic and clastogenic potential of Attalea phalerata Mart. ex Spreng. oil pulp in vitro and in vivo experimental models. PLoS One. 2016;11(10):e0165258.

Georgé S, Brat P, Alter P, Amiot MJ. Rapid determination of polyphenols and vitamin $\mathrm{C}$ in plant-derived products. J Agric Food Chem. 2005;53(5):1370-3.

Gomes FdS. Carotenóides: uma possível proteção contra o desenvolvimento de câncer. Rev Nutr. 2007;20(5):537-48. 
Grangeiro A, Queiroz A, Figueiredo R, Mata ME. Viscosidades de polpas concentradas de figo-da-índia. Curr Agr Sci Technol. 2007;13(2):219-24.

Jun-xia X, Hai-yan Y, Jian Y. Microencapsulation of sweet orange oil by complex coacervation with soybean protein isolate/gum Arabic. Food Chem. 2011;125(4):1267-72.

Kralovec JA, Zhang S, Zhang W, Barrow CJ. A review of the progress in enzymatic concentration and microencapsulation of omega-3 rich oil from fish and microbial sources. Food Chem. 2012;131(2):639-44.

Laine P, Toppinen E, Kivelä R, Taavitsainen V-M, Knuutila O, Sontag-Strohm T, et al. Emulsion preparation with modified oat bran: Optimization of the emulsification process for microencapsulation purposes. J Food Eng. 2011;104(4):538-47.

Luo Y, Zhang B, Whent M, Yu L, Wang Q. Preparation and characterization of zein/chitosan complex for encapsulation of $\alpha$-tocopherol, and its in vitro controlled release study. Colloid Surface B. 2011;85(2):145-52.

Maria do Socorro MR, Alves RE, de Brito ES, Pérez-Jiménez J, Saura-Calixto F, Mancini-Filho J. Bioactive compounds and antioxidant capacities of 18 non-traditional tropical fruits from Brazil. Food Chem. 2010;121(4):996-1002.

Menezes CRd, Barin JS, Chicoski AJ, Zepka LQ, Jacob-Lopez E, Fries LLM, et al. Microencapsulation of probiotics: progress and prospects. Cienc Rural. 2013;43(7):1309-16.
Nori MP, Favaro-Trindade CS, de Alencar SM, Thomazini M, Balieiro JCC, Castillo CJC. Microencapsulation of propolis extract by complex coacervation. LWT-Food Sci Technol. 2011;44(2):429-35.

Prata A, Grosso C. Production of microparticles with gelatin and chitosan. Carbohyd Polym. 2015;116:292-99.

Rodriguez-Amaya DB. Quantitative analysis, in vitro assessment of bioavailability and antioxidant activity of food carotenoids-A review. J Food Compos Anal. 2010;23(7):726-40.

Rutz JK, Borges CD, Zambiazi RC, Crizel-Cardoso MM, Kuck LS, Noreña CPZ. Microencapsulation of palm oil by complex coacervation for application in food systems. Food Chem. 2017;220:59-66.

Shahidi F, Janitha P, Wanasundara P. Phenolic antioxidants. Crit Rev Food Sci Nutr. 1992;32(1):67-103.

Wieland-Berghausen S, Schote U, Frey M, Schimdt F. Comparison of microencapsulation techniques for the watersoluble drugs nitenpyram and clomipramine $\mathrm{HCl}$. J Control Release. 2002;85(1):35-43.

Zhang Z, Huber DJ, Qu H, Yun Z, Wang H, Huang Z, et al. Enzymatic browning and antioxidant activities in harvested litchi fruit as influenced by apple polyphenols. Food Chem. 2015;171:191-99.

Received for publication on $28^{\text {th }}$ February 2017 Accepted for publication on $03^{\text {rd }}$ August 2018 